Pex Cult. 2014 December; 18(4): 570-891. doi:10.1007/s12119-014-9227-4.
Partnerships between Black Women and Behaviorally Bisexual
Men: Implications for HIV Risk and Prevention
Nina T. Harawa, PhD, Nora B. Obregon, PhD, and William J. McCuller, MA
Department of Research, College of Medicine, Charles R. Drew University of Medicine and
Science, Los Angeles, California
Abstract
Although an estimated 87\% of new HIV infections in Black/African American women are
attributed to sex with men, many women are unaware of their male partners' HIV risk factors.
Research on women who are aware of a high-risk male partner may inform HIV prevention. We
analyzed transcripts from semi-structured interviews with 20 Black women who reported sex with
at least one man who had sex with men and women (MSMW) in the prior 5 years. We applied
Choice and Sexual Network theories to the interpretation. The majority described their
partnerships as committed and involving emotional or instrumental support. Substance abuse was
a common component of the relationships and very few involved consistent condom use.
Although nearly all respondents described it as alarming to learn of their partners' involvement
with other men and several ended the relationships, many continued the relationships without
protective changes in their sex behavior. These narratives indicate that although many leave, many
other women remain in relationships after learning of a male partners' high-risk activity.
Substance abuse, financial instability, and a desire to remain in intimate partnerships may
discourage preventive actions in these women.

\title{
Keywords
}

bisexuality; risk factors; Black/African American; HIV infections/prevention \& control/ psychology/transmission; interviews as topic

Black women have experienced disparities in HIV risk nearly since the US epidemic's start (Centers for Disease Control and Prevention (CDC), 2011; CDC, 2009; Tillerson, 2008). In recent years, this burden has become a major concern in African American communities and a greater focus of intervention efforts. Nevertheless, many sexually active Black women do not personalize this risk (Bowleg, Belgrave, \& Reisen, 2000; Crosby, Yarber, DiClemente, Wingood, \& Meyerson, 2002; Paxton, Williams, Bolden, Guzman, \& Harawa, 2013; Weis et al., 2009) and condom use is not the norm in ongoing adult heterosexual partnerships of any race/ethnicity (Reece, Briggs, Dodge, Herbenick, \& Glover, 2010). One challenging aspect of perceiving oneself or one's partner to be "at risk" is recognizing and accepting the factors that may contribute to that risk. This can have enormous personal and relationship costs

All correspondence regarding this manuscript should be directed to: Nina T. Harawa, Associate Professor at Charles Drew University of Medicine and Science located at 1731 E. 120th Street, Building J, Rm 17, Los Angeles, CA 90059. Or call or email at 323-357-5899, ninaharawa@cdrewu.edu, fax 323-563-4945. 
because many risky activities involve violations of normative expectations for one's relationship, gender, or community status. This may be acutely true for Black women with male partners who have engaged in same-sex activity.

Nearly, two-thirds of female HIV/AIDS cases occur in Black women, and the CDC attributes a large majority of these to sex with a man (CDC, February 2013). CDC transmission risk categories for these male partners include those known to be in HIV behavioral risk groups (e.g., injection drug users (IDUs), men who have sex with men (MSM)) and those known to have HIV but whose behavioral risk group is unknown (CDC, 2009). In 2006, $10 \%$ of cumulative HIV (non-AIDS) cases among Black females were attributed to male sex partners in known high-risk groups; $36 \%$ to HIV-infected male partners with unknown/unspecified risk; and 39\% to unspecified risk factors (generally male partners with both unknown HIV status and unspecified risks) (CDC, 2009). Although just $3 \%$ of female cases were attributed to sex with men who have sex with men and women (MSMW) (CDC, 2008), there are large proportions of unknown/unspecified risk group cases in HIV-positive women and an elevated HIV prevalence in MSMW relative to heterosexual men (CDC, 2001, 2010; Gorbach, Murphy, Weiss, Hucks-Ortiz, \& Shoptaw, 2009; Klevens, Fleming, Neal, \& Li, 2001; Schmidt \& Mokotoff, 2003). Furthermore, there are 3.9 and 6.1 times as many Black MSM as there are Black heterosexual men and Black male IDUs, respectively, among estimated new HIV infections in the US (CDC 2012). According to National HIV Behavioral Surveillance data, 21\% of Black MSM in 21 US cities had a female sex partner in the prior 12 months (CDC 2011b). Hence, the numbers of Black MSMW in the U.S. who are living with HIV is likely similar to those of Black heterosexual men or Black male IDUs. All of these data suggest that more than 3\% of HIV cases in Black females could be attributed to sex with MSMW.

Qualitative studies have explored self-identification, HIV risk perception, experiences of bi/ homophobia, and gender expectations in MSM who are behaviorally bisexual, non-gayidentified or both (e.g., (CDC, 2008; Dodge, Jeffries, \& Sandfort, 2008; Goldbaum, Perdue, \& Higgins, 1996; Harawa, Williams, Ramamurthi, \& Bingham, 2006; Harawa et al., 2008; Jeffries, Dodge, \& Sandfort, 2008; Lichtenstein, 2000; Schrimshaw, Siegel, \& Downing, 2010; Stokes \& Peterson, 1998; Washington \& Brocato, 2011)). These studies indicate that financial hardship, substance abuse, exchange sex, HIV stigma, and societal perceptions of masculinity and bi/homosexuality are often important concerns for MSMW. According to Sexual Network Theory, individuals frequently partner with others who have similar sociodemographics and behavioral characteristics to themselves (homophily) and engage in sexual behaviors that are influenced by the norms of their social networks (Edward O. Laumann, Gagnon, Michael, \& Michaels, 1994). In this regard, Black women who have experienced financial hardship, substance abuse, or exchange sex themselves may be overrepresented in Black MSMWs' sexualsocial networks. For example, Gorbach et al's research with predominately lower-income substance-using men in Los Angeles (53\% Black, 38\% MSMO, 41\% MSMW, and 21\% MSW) found that most also had substanceusing partners (Gorbach et al., 2009). The behavioral and social norms within Black MSMW's networks will be influenced by the instability and other consequences associated with these factors, as well as, a desire to fulfill masculine and heterosexual norms, such as 
being the insertive partner, controlling female partners, and having children (Whitehead, 1997).

Despite increased HIV-related research on MSMW over the past 10-15 years, very little HIV research has focused on the sexual experiences of women in the US who have had MSMW partners, contributing to the dearth of information about women's partnerships with men in high-risk groups. One risk-focused study on female partners of MSMW involved students attending historically black colleges. Those participants who reported MSMW partners were more likely than those who did not to report both risky and protective factors (Voetsch et al., 2010). It is reasonable then to expect that female partners of MSMW are diverse in their levels of HIV awareness and personal barriers/motivators to prevention. Exploring the relationship experiences of HIV-negative and positive female partners of MSMW will elucidate the priorities of these women and the risky and protective characteristics of these partnerships.

Research examining relationship narratives among other groups of at-risk women has illustrated that substance abuse, gender role expectations, financial needs, perceived partner availability, and a desire to be in a traditional conjugal union influence the types of partners women seek out, the behaviors they expect and tolerate from partners, and their decisions regarding condom use and HIV/STD testing (Bowleg, Lucas, \& Tschann, 2004; Comfort, Grinstead, Faigeles, \& Zack, 2000; Jarama, Belgrave, Bradford, Young, \& Honnold, 2007; Maxwell \& Boyle, 1995; Paxton et al., 2013; Sobo, 1995). The current study expands this literature by focusing on women who have sex with men who have sex with men, a group whose own behaviors and perceptions may be further influenced by messages from both public health entities and the popular media regarding the HIV risks associated with their partners' same-sex activities. In April 2004, Oprah Winfrey brought widespread attention to Black men who present themselves as heterosexual and have female partners but also engage in sex with other men when her show featured, JL King, author of "On the Down Low: A Journey into the Lives of 'Straight' Black Men Who Sleep with Men." Numerous media accounts followed, as did increased attention from public health and research communities. The CDC even references the phenomenon in several sections of its website. Much of the media discussions and even the public health discourse was subsequently critiqued for casting Black men as "generally excessive, deviant, diseased, and predatory." (Ford, Whetten, Hall, Kaufman, \& Thrasher, 2007, p. 209). Hence, Black women have been told both by popular media and by public health entities that Black MSMW pose a major threat to their health and, in many cases, have been presented narrow, morally corrupt images of these men.

\section{Theoretical Orientation}

We used two theoretical perspectives to guide our thinking and data analysis. Choice Theory, which stems from economics, has been applied to decision-making regarding choice of sexual partners (Laumann et al., 1994). Sexual Network Theory, first used to describe social networks, has been used to describe the influence of partner availability and social factors on partner selection and behaviors within partnerships (Laumann et al., 1994) and to explain racial differences in STD rates in the US (Laumann \& Youm, 1999). Sexual 
Network Theory was used in developing our interview questions, and elements of both explanatory models emerged as relevant through analysis of our interviews with African American female partners of MSMW. Choice Theory suggests that personal goals (e.g., security, orgasm, parenthood, getting high) and resources (e.g., time, mobility, money, and reputation) shape partner choices much as they do choices related to acquisition of goods and services (Laumann et al., 1994). Individuals make choices between the potential social, economic, and emotional costs and benefits of engaging with specific potential partners and take actions to minimize the costs and maximize the benefits of sexual partnering. In these processes, they are limited by the resources they have to invest in both findings and in finding out about potential partners, their expectations of the marketplace, and its size and composition. Sexual Network Theory speaks to the social nature of sexual partnerships and the ways in which social forces influence who is most likely to engage in sexual partnerships by constraining partner availability and by discouraging or encouraging particular types of unions and behaviors through the influence of social network members (Laumann et al., 1994).

\section{Method}

\section{Recruitment}

The Charles R. Drew University of Medicine and Science Institutional Review Board approved the study. Potential study participants were recruited throughout Los Angeles through advertisements on Craigslist.com and in community newspapers and magazines and flyers posted and distributed at health fairs, educational events, HIV and other health clinics, Laundromats and general community venues. In addition, brief study presentations were conducted with staff of various clinics to encourage patient referrals. A community advisory board, comprised of local providers and activists, also encouraged referrals, informed outreach approaches and the interview guide. Promotional materials encouraged calls from women who had ever been in a sexual relationship with a man who they knew or suspected had also been involved with other men. Outreach was conducted concurrently for a second arm of the study on HIV-positive women with unidentified sexual risk. Eligibility for both arms was determined by screening interested callers over the telephone. All participants for this analysis were 18 years or older, female (not transgender), self-identified as Black/ African American and had been tested for HIV within the past 24 months. In addition, participants had to have had anal, vaginal, or oral sex with an MSMW in the prior 5 years regardless of whether or not they were currently involved with that partner. Eighty-nine African American women were screened for one of either arm of the study, of whom 27 were determined eligible and 21 interviewed for this arm. Six participants were unable to successfully schedule and complete the interview and one participant was dropped because her interview indicated that she did not, if fact, meet the eligibility criteria. Of the 20 eligible participants, 6 were recruited from Craigslist.com, 5 from outreach by health and social service providers serving indigent populations in the downtown area, 4 from health clinics located elsewhere, including HIV clinics, and 5 from other sources (e.g., drug treatment program, community college, another participant, or recruiter). 


\section{Measures and Procedures}

Data Collection-Data were collected from September 2009 to November 2010. A oneon-one, in-person interview was conducted in a private office at Charles Drew University or the participant's home and they were digitally recorded. The interviews took a mean of 71 minutes (range $=42$ to 107 minutes). Although participants were to be matched with an interviewer of the same gender and race, two were interviewed by a Latina female because they had a professional relationship with the African American female interviewer (Author: REDACTED).

Once the interview was completed, participants completed a brief, self-administered handwritten survey with 28 close-ended questions on sociodemographics, HIV/STDs (last HIV test and results, STD history), and related risk factors (i.e., sexual activity, substance use, condom use, exchange sex for the prior 2 years).

Semi-Structured Interview Guide-The interviewer used a semi-structured guide to lead participants through the interview while leaving room to discuss other topics. The interview guide was designed to initiate discussion surrounding the progression of each participant's relationship with her MSMW partner from start to finish. Details of the current or most recent relationship were discussed such as how the two met and became involved, the type and length of the relationship, their sexual activities and condom use, when and how the participant learned of her partners' same-sex activity, and her responses to this information. As applicable, prior relationships with other MSMW were also examined; however, due to poor recall and time constraints, information on the more distal partnerships was sometimes less detailed or complete. Additional items included the number and types of other sexual relationships the participant had had in her lifetime, her sexual risk history, and her general attitudes regarding infidelity, HIV risk, and condom use. Based on information from the first set of completed interviews, the guide was modified to capture additional, potentially relevant information on the partners. Please see Appendix 1 for the original guide.

Analysis and Reliability-All interview recordings were professionally transcribed. To prepare the data for analysis, we used software designed to manage qualitative information and produce queried reports based on users' input (Atlas.ti). First, we developed a codebook with 13 broad codes (or domains) based on the interview guide questions related to the partnerships with MSMW (e.g., "initial attraction" - see Results headers for the other domains discussed here). Second, we ensured all coders were familiar with the codebook and applied the codes consistently. To do this, 1 transcript was coded individually by each of the 3 coders (coauthors) who then met to review the accuracy of this first round of coding and refine the codes. Each quotation was reviewed and any discrepancies were discussed until all coders were in agreement with code definitions and their application. This process was then repeated twice with different transcripts. Third, all 20 transcripts (including the 3 used for training) were assigned and coded separately using the refined codebook; 2 coders each coded 7 transcripts and 1 coder coded 6 transcripts. 
The coders also summarized the transcripts in MS Excel with an individual column representing a set of responses for each of the MSMW partners reported by the participants. Subcodes, based on team discussions, were created and used for responses to each of the 13 domains (e.g., "easy to talk to" or "easygoing/mellow" for "initial attraction"). Throughout the coding process, the coders met to review each transcript, discuss the subcodes and verify their accuracy as they related to each domain (all coders in agreement). Finally, they tallied the numbers of partnerships and MSMW partners (denoted with p) and study participants (denoted with $\mathrm{n}$ ) that applied to each code in order to establish the frequency and range of specific responses within each domain. The sample was then stratified into those participants who did and did not mention illicit drug use -- a major factor that emerged as influencing the partnerships. Because so little is known about the target population, we include a substantial amount of descriptive data, including the frequencies of relevant characteristics for participants and reported relationships/partners. These data, together with the representative quotes, labeled with pseudonyms, provide additional information on the life/relationship circumstances of the women and their bisexual partners.

\section{Results}

\section{Participant Backgrounds ( $\mathrm{n}=\mathbf{2 0})$}

Participants ranged in age from 18 to 58 years (average $=38.8, \mathrm{SD}=11.9$ ). The majority (19 of 20) identified as heterosexual on the quantitative survey. All reported recent vaginal sex with a male; 18 also reported oral sex, and 3 also reported anal sex. The average number of recent male partners was 3.7 (range: $1-20 ; \mathrm{SD}=4.3$ ), and 3 participants also reported recent sex with females. Three of the participants were HIV positive.

Although socioeconomic status (SES) was not directly assessed, many participants mentioned during qualitative interviews having experienced financial instability, housing instability, or receiving public assistance. When asked, 8 participants reported having exchanged sex for money or drugs; 4 reported incarceration; and 14 reported illicit drug use during their lifetimes. Crack and/or powder cocaine were the most commonly used drugs $(n=9)$. Marijuana $(n=4)$, heroin $(n=2)$, methamphetamine $(n=2)$ and ecstasy $(n=2)$ were also reported. Participants' number of reported lifetime male sexual partners ranged from 2 to 150, with 10 participants reporting greater than 10 male partners in their lifetimes. Although not a specific interview question, a number of participants mentioned having experienced sexual abuse $(n=4)$ or domestic violence $(n=7)$.

\section{How They Met the MSMW Partners $(p=31)$}

The 20 participants discussed sexual partnerships with 31 different known MSMW. Eight participants reported multiple relationships with MSMW, all but one of these women reported illicit substance use. Five reported two, one reported three, and one reported five different MSMW partners. In addition, one woman reported having had sex with dozens of men who she knew or assumed to be MSMW but only provided details on one of these partnerships. Table 1 illustrates details regarding these 31 relationships including how the participants met the men. Several did so through their friends and family, "on the street" (e.g., walking by), or in a store- generally in their area of residence, including two liquor 
stores and a thrift store. A small number of participants reported meeting their partner when they bought or sold drugs from or to the men. Others met the MSMW through shared housing circumstances. For example, 2 of the 3 participants who met their partners through school did so in their dormitory complex; others did so while in the same drug treatment, drug recovery, or transitional housing facility. Just 1 participant reported meeting her partner through her formal employment. None met through other common venues for finding partners such as the Internet, church, or social organizations.

\section{Partnerships with MSMW $(p=31)$}

The majority of the relationships with MSMW had lasted more than six months and were considered by the women to have been serious (including both engagements, marriages, and cohabitations). However, the substance-using women reported a substantially higher proportion of casual relationships. Although 6 relationships involved some exchange of sex for drugs or money, only one was strictly commercial. Six participants had had biological children with their MSMW partners, some others shared in raising non-biological children.

The MSMW partners were mostly African-American ( $\mathrm{p}=22$ ); 2 were White, 3 were Latino, 1 was Asian, and 3 were not discussed. Twenty-one partners were known to have used illicit substances or drink heavily. Among the 16 who used substances other than just marijuana or alcohol, powder or crack cocaine ( $\mathrm{p}=9)$, ecstasy $(\mathrm{p}=2)$, heroin $(\mathrm{p}=4)$, or methamphetamines $(\mathrm{p}=3)$ were reported. Five partners did not use substances, and substance use type was not known or reported for another five. Four partners were known to have HIV; however, the MSMW partners' HIV status was unknown to several participants. Two thirds $(\mathrm{p}=20)$ of MSMW partners had a history of incarceration; 17 in prison. Seven had no history of incarceration; incarceration histories were unknown or unreported for 4. Study participants described partner incarceration as if it was commonplace among men in their networks. A number also mentioned incarceration disrupting ongoing partnerships or contributing to same-sex behavior among men. For example, Ebony, who was married for 14 years to an MSMW responded as follows when asked whether he was ever in prison or jail (age 45):

Most of his life, in which he informed me that he had a boyfriend in there, the dominant kind. From what I had sensed is that I think he started hit him, or hurt him. You know dominate him. You know? So then, when we got married, I mean, you couldn't even get too close before he thought you were like gonna slap him or something.

Most of the partners were formally employed ( $\mathrm{p}=17$ ), five were unemployed, and employment status was not discussed for 9 partners; however, informal income sources (including drug dealing) were mentioned for some.

\section{Initial and Sustained Attraction to MSMW Partners $(p=31)$}

In response to questions about what attracted the respondents to the partners, participants listed a range of characteristics consistent with personal objectives of companionship, sexual pleasure, security, and support, but they rarely discussed having been the ones to pursue the relationship. Several participants felt attracted to the men initially because they were nice, kind/caring, sincere/honest, or attentive. Participants also reported attraction to the men's 
physical attributes (including masculine traits or "style" (e.g., dancing skills, accent or grooming). Many initially liked the fact that the men were easy to talk to and provided emotional and moral support:

Briana (age 25, in an intermittent 5-year relationship with the MSMW): We could just talk about anything before we even became lovers; we had been together two years ... before we even had a child. And we could just sit up and talk about anything. We read books, you know. We just had a lot in common, and that's what I liked.

For three women, financial support or access to drugs were their sole reasons for being attracted to the MSMW ( $\mathrm{p}=6$ in total); however, the women sometimes became emotionally involved later. For Ebony, age 45, an offer of financial assistance by a smitten thrift store security guard helped the relationship solidify quickly despite the man's own fragile circumstances:

So I was like, 'You know what, what you could do for me, if you really wanna help me that bad is pay my car note this month, which is $\$ 200$.' He said, 'Oh, it's $\$ 200$ ?' I said, 'Yes sir. I'm homeless and my car note is due.' He said, 'Well, you come here tomorrow $\ldots$ and I'll give you the money to pay your car note.' I said, 'Oh wow, really?' He said, 'Yeah, my car is getting fixed in the shop as it is, and my house just burned down. So now, I gotta stay here at the mission.' And I'm thinking to myself, 'Okay, security.' The car note being paid, we were married that Friday.

Support, whether financial or moral, emotional, and logistical, also played a major role in sustaining several women's partnerships, as did their partners being easy to talk to/ comfortable to be with or friends before the relationship began. Additional reasons provided for several participants' sustained attraction to the partners were their being attentive/ affectionate, nice, kind/caring, protective, sincere/loyal/trustworthy, or their treating the participants and their families well.

\section{Perceived Exclusivity with MSMW Partners $(p=31)$}

Nearly half of the relationships were perceived by participants to involve a commitment that precluded both parties from having sex with others. When asked whether or not they had an explicit agreement about this, Keisha (age 51) responded, "We know we're only with each other. We talk about it all the time." Among the relationships where exclusivity was not expected, there were 5 where the participant suspected her MSMW partner had other female partner(s), 6 where she knew this was the case, and 2 where she did not expect exclusivity because the relationship was casual or involved commercial sex. In five relationships, the participants themselves had sex with others.

Only two women in the perceived non-exclusive relationships anticipated that the other person could be a male, and many of the others found this realization particularly painful. Below, Nicole (age 51, 4-year cohabitation with the MSMW) responds to a question about how she felt after her partner started openly having sex with men in addition to the women, she already knew he was engaging with: 
And see, I don't knock on the door. I just open and go in and there was somebody [a man] in there with him. And I'd be like, 'Ah.' Yeah, so it hurt. It hurt. But I drowned my sorrow with drugs and alcohol to make it okay $\dot{A}$

Other participants did not, however, view a partner's engagement in sex with other men very differently than they viewed it with other women. Alisha (age 27, in a 4-year intermittent relationship with the MSMW) shared the following exchange that occurred after questioning her partner about a recent video he showed her of himself kissing another man:

He finally responded, 'Well, I used to date guys on a regular basis' - or not fully date them. But then I asked him, does he still do it? He said, 'Sometimes.' I didn't really feel that was cheating because I thought he [just] was having fun.

This young woman was part of a rave social network that frequented clubs and used party drugs. Although she was in an ongoing, serious relationship with the partner mentioned in this quote, the casual "anything goes" norms of her network seemed to permeate her response to his infidelity and engagement in sex with other men.

All but one of the perceived, non-exclusive relationships involved substance-using women. A number of these women mentioned priorities that did not require exclusivity, as is seen most starkly in Nicole's statement (age 51, 4-year cohabitation with the MSMW):

This person I was in a relationship with, he was a big-time drug dealer. And I was a big-time dope fiend. So I used my skills to get in ... and I was at first a chick on the side. But it didn't matter because I was only there for one purpose and one purpose only.

\section{Condom Use in Relationships with MSMW Partners $(p=31)$}

Most relationships involved either no or inconsistent condom use (18) throughout. The two main reasons our participants gave for not using condoms consistently were that they were in a committed relationship with the MSMW partner (9) - Danielle (age 38): "I mean, if we're in a relationship, why do you have to use rubbers and why do I have to use rubbers?" -- or they rarely to never used condoms with anyone (9). Women in the latter group frequently did not consider their HIV/STD risk (Marla, age 52 -- "No, condoms, nobody talked about no condoms.") or disliked condoms because they perceived them to be unpleasant. In another 5 relationships, condom use changed from one point to another. For example, condom use declined as the relationship became more serious and committed or was restarted because the participant contracted an STD from the man or was suspicious that he had cheated on her (Dashawna, age 28, --"Especially if I was not sure about his whereabouts or whatever. Yeah, I would [use a condom].”).

In 4 ongoing relationships, the participants also did not use condoms because the partners had received HIV/STD testing and/or appeared healthy. Below, Earlene (age 40, 1 year relationship with the MSMW) discusses how she concluded it was safe to forgo condoms with her partner initially even in the face of other information about the man's potential risk factors, including recent unprotected sex with another woman, unstable residence, and suspicious behaviors: 
Honestly, we started off not using them. It is really just to my own ignorance... I thought well he just had a baby. He looked healthy. He was an athlete too. And also I know when you participate in certain sports if you're active, they do their own testing I figured, and he had said that he had been to the doctor. He'd been tested for everything and that whole thing ...

We also observed other instances where women who would forgo condoms seemed to discount negative and focus on positive information about the partner. In other relationships, women did not use condoms consistently because they sometimes did not have one available, were intoxicated, "slipped", or felt unable to negotiate this with their partners.

\section{Participant Control over Condom Use in Partnerships $(p=31)$}

Participants in 11 relationships seemed to have full control over condom use with their MSMW partners and at least some control over it in 10 others. When asked about what made her so conscientious about using condoms and HIV testing, Alisha (age 27) replied, "I just think it's the right thing to do. I mean, I really don't wanna catch anything". She, like some of the other users interviewed, described condom use as a non-partner-specific action that she was in control of and took to protect her health. In 4 relationships, participants never discussed or thought about using condoms with the MSMW partners. In only 2 relationships did participants express wanting to use condoms but lacking control over condom use.

Participants also showed a fair amount of autonomy over other aspects of their sexual health and a desire to know more about a partner before making a risky investment in unprotected sex. For example, although several resisted questioning their partners' sexual histories, a number had asked partners their HIV/STD status or insisted they obtain testing, including Danielle (age 38) who was in a 2-year relationship with an MSMW involving exchange sex:

Interviewer: Did you ever talk about your sexual histories?

Danielle: No.

Interviewer: Who he'd been with before? How many women? If he'd ever been with a man?

Danielle: That's what I didn't do. But I took him to the place to get a HIV test before I started messing with him. I said, 'You gotta go get checked.'

\section{Learning of Partners' Same-Sex Behavior $(p=31)$}

In nearly all of the relationships with MSMW, participants only learned of their partners' engagement in sex with other men after the relationship began. In nearly half of the relationships, women found out that their partner was an MSMW because someone else told them. This person was either a family member or friend $(p=9)$ or a current or former partner of the man ( $\mathrm{p}=5)$. After receiving the information, some participants either denied it or looked for evidence to confirm it. Dana, age 45, in a casual relationship for 6 months with this MSMW, described part of her experience as follows: 
Dana: I met him at a club, and everything was going well, and then I kept - he just started, his attitude changed, and then I found out - a friend of mine told me - he had a boyfriend. He was gay.

Interviewer: So you said a friend told you. [Did] you ever have confirmation whether it was true?

Dana: Yeah, I caught them together hugging, that's enough for me.

Not only did Dana find out about the other man through her social network, but the fact that a friend felt the need to report this information to her and that the respondent chose to respond as she did indicates that his actions were not acceptable to the norms of that network.

In 10 relationships, the partners themselves disclosed their same-sex activities. However, in half of these cases, his disclosure only occurred after she had been told by others or circumstances made it likely that the participant would soon find out through other means. For instance, Ebony found out gradually. She said that that family members and friends told her that her husband was with other men, and men would visit her home and act jealous of her. Eventually, she asked him and he disclosed. In 7 of the 31 relationships, participants discovered their partner had sex with men because they incidentally found the man in bed or in another compromising situation with another man. When asked if she had ever wondered about her partner's sexuality prior to finding out, Edwina age 58, who was in an intermittent 35-year relationship with the MSMW responded:

No, no, never, ever, ... How I found out is that I came home from work ... and they were in my bedroom. I'm saying, 'What are you all doing in here?' He just went off, and to me, he always told me, 'the best defense is good offense,' or whatever that whole mess is. Then he gets mad first. So when he got mad first, I know something's wrong.

She and a number of other women were unsuspecting even though the MSMW partners were engaging in sex with other men that the women, themselves knew as friends, drugusing partners, or coworkers.

Two participants learned their partners were MSMW because they grew suspicious on their own and then looked for and found corroborating evidence. Just two participants knew or assumed from the beginning that the partners were MSMW. In an additional relationship, also referenced above, a partner told the participant before they married that he had gotten high and engaged in same-sex activity in college but "left that behind him." She believed him and denied any knowledge of ongoing same-sex activity until a scandal erupted over him engaging in sex with teenage boys. Finally, one participant did not suspect that one of the three partners she discussed was an MSMW; however, this was known to her interviewer because of the man's participation in another study for MSM. 


\section{Responses to Learning of Partners' Same Sex Activity $(p=31)$}

Participants who learned of the partner's MSMW activity later in the relationships ( $\mathrm{p}=25$ ) had varied and sometimes multiple responses to the information. In some relationships $(\mathrm{p}=7)$, the participants confronted the men. In some relationships, participants took healthprotective steps -- 8 tested for HIV, 2 started to use condoms, and 3 engaged in sex less frequently or stopped having sex with that partner, in part because they felt less attracted to the man after learning that he had had male partners. Earlene both used condoms and had less sex:

And the few times we did it was, I was reluctant, hesitant, wasn't interested. And, you know also, I made him wear protection... So there still was that doubt about his sexuality or his activity that he was doing. But I figured if I was going to do it I was at least going to protect myself.

A few women, however, had already tested negative for HIV or knew that they or their partners had HIV. In eight relationships, the participants broke up, filed for divorce, or separated from the partners soon after learning that he had sex with men; some others stayed before leaving for this reason $(\mathrm{p}=4)$. Participants who discovered, rather than being told by the partner of his same-sex activity were more likely to leave, citing feelings of betrayal. In many other relationships $(\mathrm{p}=11)$, the participants stayed with the partner.

Common emotional responses to learning their partner was an MSMW were sadness, anger, shock, and betrayal. An example is Edwina's explanation of why she described herself as feeling hurt:

Because when I asked [about his sexual history], he could have told me. He could have told me. He knew about mine. I was with a female for 6 years, 7 years, and I told him. I feel like when you start a relationship, you try to be as honest as possible.

Many participants described the discovery as conflicting with their sense that the men they were with were caring, supportive, or trustworthy. "I just gave up. I just said, you know, I really cared, and I didn't think you would hurt me like that to be cheating with another man." Dana, age 45, responded when discussing her response to finding out that a man she was in a long-term relationship with was an MSMW. Some women discussed feeling ongoing shame, and few had shared the experience extensively. For example, although 14 participants had told at least one person that they had been with an MSMW, many of these said that they were uncomfortable telling other people, and just 9 had informed their doctors.

In two cases, participants felt closer or had added respect for the partner after his disclosure. Their experiences have important implications for prevention. Keisha, age 51, who met her current MSWM partner while they were both in residential drug treatment, described her experience as follows:

It took about a month after we got out, got tested [for HIV], and then he started telling me stuff. ...He told me that he's a man, he's a full man, but he was in prison for 15 years, and he missed being with a woman, and things just happened. And he's not proud of it, but they happened and they're in the past, so I let them stay in 
the past. I was like, 'my God, you're so manly.' But I didn't hold it against him. People make mistakes.

She later continued with:

Just the thought that he felt comfortable enough or cared about me enough to tell me, I give him that respect as a man.

In this case, the partner's willingness to share this information reinforced to the participant that he cared for her and trusted her. She returned this trust by respecting him "as a man," which included her not considering the possibility of any ongoing or future sexual activity with other men. The couple, who had been together for a year and were both new to sobriety after long histories of substance abuse and life on the streets, used condom inconsistently.

\section{Discussion}

Consistent with Sexual Network and Choice theories (Laumann et al., 1994), the female partners of MSMW we interviewed generally discussed men who were similar to themselves in their race and substance use histories. Consistent with Choice Theory the women's personal goals and resources seemed to influence what they found attractive in the MSMW partners, the measures they took to minimize their sexual and emotional risks, and the costs and benefits they assessed regarding whether or not to remain in specific partnerships. Although much of the sexual network research highlights reasons for homophily or a preference for partnering with similar individuals from one's own social network, it also indicates that those engaged in infidelity may select partners from different networks in order to avoid detection (Laumann et al., 1994). Male sex partners of MSMW represent an exception, as men can spend a great deal of time interacting with other men from their regular social networks before engendering a female partner's suspicion of infidelity.

Where and how participants met the MSMW partners was influenced by the women's life circumstances including her socioeconomic status (e.g., frequent residence in low-income neighborhoods where unemployed men spend time hanging out on the street) and social networks (mainly friends and family). In some cases, substance use brought the individuals together because they met in settings of drug use or recovery or through. Substance abuse combined with financial instability encouraged some participants to enter or stay in partnerships with MSMW who could provide access to drugs or other resources (e.g., housing, transportation). However, even study participants who were financially stable reported sometimes overlooking information about their partners that signaled infidelity, risky behavior, and other undesirable traits. When she identified this same tendency in her interviews with low-income African American women in the 1990s Elisa Sobo (1998), described it as reflecting the women's response to social norms that view male partners' traits as negative or positive reflections on the women themselves. Women are therefore motivated to downplay potential negative traits because of the implications for their own self-image and reputation.

Our findings are consistent with the little existing research on female partners of MSMW. Voetsch's (2010) study of black female college students found that these women were more likely than other women to report multiple sex partners, recent unprotected sex, being in a 
committed relationship and increased HIV risk perception. There are also consistencies with recently published data from a secondary analysis of 15,625 tests to sexually active females at publicly funded HIV testing sites in Los Angeles County (Harawa, McCuller, Chavers, \& Janson, 2012). Women with MSMW partners were more likely than other women to report current homelessness and recent illicit drug use, anal sex, multiple partners, exchange sex, and partners with other HIV risk factors (i.e., IDU, sex work and HIV infection). Less than $15 \%$ used condoms consistently with their MSMW partners. The qualitative interviews with female partners of MSMW partners reported here also included many women who do not use condoms consistently, report these risk factors, and were in what they perceived to be committed relationships. These qualitative data indicated that substance-using women may be more likely than other women to come in contact with and engage in relationships with MSMW some are willing to engage in sex with a known MSMW (as MSMW have reported in other research (Harawa et al., 2008)), tolerant of men who have concurrent partners (as was the case in our sample), or part of social networks with higher proportions of MSMW.

The narratives discussed here also provide detailed and holistic descriptions of the women and their partnerships with MSMW. Not only were many of the partnerships serious, they often fulfilled a need for financial, logistical or emotional support. The supportive factors may have been particularly important for the study participants who often described challenging life circumstances -- including financial hardship, single motherhood, and histories of trauma -- that the partners' presence had the potential to ease. Low SES is a well-documented HIV/STD risk marker for women and male and female heterosexuals in the United States (CDC, 2011; Ickovics et al., 2002; Murrain \& Barker, 1997; Simon, Hu, Diaz, \& Kerndt, 1995). Given that our respondents also indicated non-financial forms of support that drew them to their MSMW partners, future interventions should attend to the role of social support in partnership choice among women. Sobo (1998) asserts that women with smaller support networks are more likely to rely on their ability to make "wise" choices about the men with whom they partner than to rely on condoms for disease protection, as they view these sexual relationships as their main sources of emotional support and condoms as symbols of mistrust.

Choice Theory would indicate that women's relationship and sexual behavior choices represent tradeoffs between the types of support received and relationship costs incurred (Laumann et al., 1994). Although our data support aspects of the theory, participants' decision-making processes and rationales were often expressed subtly. Participants rarely discussed going through a careful, conscious assessment of how well a given potential partner could fulfill their objectives. This may be because the women often had been the ones pursued rather than pursuing the partners discussed or they lacked the time or finances to invest in determining whether or not a potential partner was ideal for them or the relationship evolved from a friendship. Further elucidating the relevance of Choice Theory would require an interview guide that more explicitly explores its various dimensions, including the value the women placed on the benefits they received from these partnerships.

The interviews further indicate that, even in a sample of women who recently tested for HIV women, health-protective measures are not always the way that women respond to finding out that a male partner belongs to this high-risk group. Participants rarely responded by 
increasing condom use, perhaps because many women place a heavy cost on condom use within ongoing partnerships as it symbolizes a failure of trust within the partnership (Sobo, 1998). Importantly, many women may not share their partners' same-sex activity with others - including their family members and medical providers. Even participant recruitment was challenging as it took over a year to recruit and interview just 21 eligible Black women despite extensive outreach efforts in a large urban center. Hence, stigma surrounding samesex activity may not only dissuade disclosure of same-sex behavior to female partners by Black MSMW but also stifle the responses of the partners themselves -- a phenomenon that may be exacerbated by women's desire to appear as wise selectors of mates (Sobo, 1998). Conducting outreach in a wide range of venues, marketing the interviews as an opportunity for women to confidentially "share their stories", using outreach staff who were also women of color, and encouraging referrals from participants, CAB members, and others facilitated recruitment and boosted trust in the study itself.

Decena (2008) critiques what he argued was a "compulsory disclosure" mandate within official public health HIV rhetoric. The rhetoric implies that full disclosure of risky activities to one's sexual partners will then lead partners to undertake disease preventive measures and is consistent with Choice Theory's assertion that more information leads to better choices. Our data argue for both the benefits and limits of such an ethic, as some participants responded to information about their partner's high-risk group membership by taking on health protective measures, but many others did not. Furthermore, prior to learning of the partners' same-sex activity, women frequently discounted information about the partners' other risk factors and focused instead on the men's positive attributes. At least 2 published studies involving large populations of low-income Black women have indicated that women who were aware that their partner was an MSMW were not more likely than other women to use condoms with their male partners (Harawa et al., 2012; Ober et al., 2011). Cochran and Mays (1993) have critiqued other behavioral theories that focus on cognitive aspects of health-related behavior. They argue that the theories ignore or minimize the worldviews and values and the often-limited access to resources and control of life circumstances of many low-income African Americans. While Choice Theory explicitly addresses how resources shape partner choice, it does not address other issues that may uniquely impact African Americans and other minorities - such as pressure to be loyal to African American communities and complex familial and religious influences. Most study participants, like most heterosexual women (Herbenick et al., 2013), either used condoms inconsistently or not at all. Condom-using participants frequently described general reproductive and health concerns as their main motivators and some reported consistent use, at least with casual partners. Hence, rather than being directly influenced by information about partners' risk histories, participants' condom use and nonuse were largely driven by personal preferences, relationship perceptions, and a desire to avoid pregnancy and HIV/ STDs, or a lack of concern about these factors. Nevertheless, new information related to the partner's current HIV/STD status or outside sexual activities, did sometimes shift our study participants' behaviors toward or away from consistent condom use. Studies also consistently show that people are less likely to use condoms in serious or ongoing sexual relationships than in short-term or casual partnerships (Anderson, Warner, \& Macaluso, 2011). 
This study has several limitations. Data on the respondent and her partners' SES were not systematically collected. In some instances, the interviews involved distant recall of information, as many respondents shared about partnerships that began several years prior; whereas, most sexual risk behavior surveys focus on the less distant past (e.g., prior 30 days to prior 12 months). In the case of multiple MSMW partnerships, incomplete information was sometimes collected on those partnerships that were more distal. In addition, not all participants had received direct confirmation of the partners' same-sex activity. Therefore, it is possible, but not likely, that some wrongly assumed this about their partners.

We further acknowledge that female partners who were unaware that their partners were MSMW might differ from those female partners who are aware. For example, longer-term partnerships may be overrepresented among aware women. Our sample included participants who learned of their partners' same-sex activities at varying points in the relationship and through various means. It included those who were told directly by the partner and those who found out through other means but whose partners had tried to keep the information a secret. It also included one woman who participated because of a former partner who she knew was an MSMW but who also discussed a current MSMW partner that she presumed to be heterosexual. Hence, we assume that many study participants may be similar to those female partners of MSMW who are currently unaware. Stigma associated with Black MSMW likely affected recruitment efforts and lead to some socially desirable responses. Nevertheless, participants frequently expressed appreciation for the opportunity to discuss the relationship(s) and nearly all seemed comfortable and candid in their responses.

As funding for outreach and prevention shrinks, the value of data on hidden, at-risk populations for guiding prevention efforts grows. The findings of this first-of-it-kind study have several potential implications. Although HIV/STD testing is a valuable prevention strategy, its benefits are limited if either partner continues to engage in risky behaviors, as was the case for many of the participants' partners. The use of "role model" stories that share examples of women who have been involved with high-risk men and addressed it in mature, health-promoting ways, may be a particularly effective and scalable method for reaching women who know or suspect they are with an MSMW but feel too confused, scared or isolated to determine and enact the most appropriate health-promoting response (CDC, 2007; The CDC AIDS Community Demonstration Projects Research Group, 1999). Such stories may also lessen the stigma that many study participants reported. Because HIVrelated sexual risks often occur in the context of substance abuse, treatment programs should go beyond provision of HIV testing to helping both women and men come to terms with the health and social implications of their and their partners' sexual histories. Finally, MSMW who play supportive roles for their female partners may be motivated to use condoms, adhere to preexposure prophylaxis (PrEP), access HIV testing, or disclose their same-sex activity and HIV status if this is promoted as an extension of their support role in these relationships. It is critical that interventions targeting MSM as a group, acknowledge that some of the participants partners will likely also be female and encourage risk reductions in these sexual encounters as well. It appears that few US-based MSM interventions currently do this; however, at least four MSMW-specific interventions have been published in the past 
four years (Harawa et al., 2013; Martinez-Donate et al., 2010; Operario, 2010), as has one intervention for serodiscordant couples (El-Bassel, Jemmott, Landis, Pequegnat, Wingood, Wyatt \& Bellamy (2010).

Despite the unanswered questions they raise, the participants' stories highlight the importance and limits of knowledge in fostering protective behaviors in individuals and emphasize the role of sociocultural context in partner choice and potential partner-related risks to women. Public health responses may include increased access to substance abuse treatment services tailored for women and structural interventions that strengthen lowincome women's economic position and access to resources. Furthermore, legal and policy interventions that lessen the imbalance of males to females in African American communities may positively shift Black women's expectations of potential partners. Because they address root issues influencing partnership selection, sexual risk behaviors, and health preventive activities, these efforts may have the greatest potential to help Black women and men make choices that protect both their and their partners' health in sexual relationships.

\section{Acknowledgments}

This study was funded by the National Institute of General Medical Sciences, award \#1 SC3 GM083780 and was supported by award \#2P20MD000182 from NIMHD. We thank Gary Ryan, Chandra Ford, and Martin Shapiro for input on drafts. We thank our community advisory board for their advice, feedback and support on all aspects of this research.

\section{References}

Anderson JE, Warner L, Macaluso M. Condom use among US adults at last sexual intercourse, 19962008: an update from national survey data. Sex Transm Dis. 2011; 38(10):919-921. [PubMed: 21934564]

Bowleg L, Belgrave FZ, Reisen CA. Gender roles, power strategies, and precautionary sexual selfefficacy: Implications for Black and Latina women's HIV/AIDS protective behaviors. Sex Roles. 2000; 42(7-8):613-635.

Bowleg L, Lucas KJ, Tschann JM. "The Ball Was Always In His Court": An exploratory analysis of relationship scripts, sexual scripts, and condom use among African American Women. Psychology of Women Quarterly. 2004; 28(1):70-82.

Centers for Disease Control and Prevention (CDC). [Retrieved November 19, 2013] Community PROMISE: Peers reaching out and modeling intervention strategies for community-level HIV/AIDS risk reduction. 2007. from http://www.cdc.gov/hiv/prevention/research/rep/packages/promise.html.

Centers for Disease Control and Prevention (CDC). HIV/AIDS Surveillance Report, 2006. 2008; Vol. 18 from http://www.cdc.gov/hiv/topics/surveillance/resources/reports/.

Centers for Disease Control and Prevention. Disparities in diagnoses of HIV infection between blacks/ African Americans and other racial/ethnic populations--37 states, 2005-2008. MMWR Morbidity and Mortalily Weekly Report. 2011; 60(4):93-98.

Centers for Disease Control and Prevention. [Retrieved May 10, 2013] New HIV Infections in the United States. 2012. from http://www.cdc.gov/nchhstp/newsroom/docs/2012/HIVInfections-2007-2010.pdf.

Centers for Disease Control and Prevention (CDC). HIV incidence among young men who have sex with men: Seven U.S. cities, 1994-2000. Morbidity and Mortality Weekly Report. 2001; 50:440444. [PubMed: 11475380]

Centers for Disease Control and Prevention (CDC). HIV/AIDS Surveillance Report, 2007. 2009; Vol. 19 from http://www.cdc.gov/hiv/topics/surveillance/resources/reports/. 
Centers for Disease Control and Prevention (CDC). Prevalence and awareness of HIV infection among men who have sex with men -- 21 cities, United States, 2008. MMWR Morb Mortal Wkly Rep. 2010; 59(37):1201-1207. doi: mm5937a2 [pii]. [PubMed: 20864920]

Centers for Disease Control and Prevention (CDC). Characteristics associated with HIV infection among heterosexuals in urban areas with high AIDS prevalence -- 24 cities, United States, 20062007. MMWR Morb Mortal Wkly Rep. 2011; 60(31):1045-1049. [PubMed: 21832975]

Centers for Disease Control and Prevention (CDC). HIV Surveillance Report. 2013 Feb.23 from http:// www.cdc.gov/hiv/topics/surveillance/resources/reports/.

Cochran SD, Mays VM. Applying social psychological models to predicting hiv-related sexual risk behaviors among African Americans. J Black Psychol. 1993; 19(2):142-154. [PubMed: 23529205]

Comfort M, Grinstead OA, Faigeles B, Zack B. Reducing HIV risk among women visiting their incarcerated male partners. Criminal Justice \& Behavior. 2000; 27(1):57-71.

Crosby RA, Yarber WL, DiClemente RJ, Wingood GM, Meyerson B. HIV-associated histories, perceptions, and practices among low-income African American women: Does rural residence matter? Am J Public Health. 2002; 92(4):655-659. [PubMed: 11919067]

Decena CU. Profiles, compulsory disclosure and ethical sexual citizenship in the contemporary USA. Sexualities. 2008; 11(4):397-413.

Dodge B, Jeffries WLt, Sandfort TG. Beyond the Down Low: Sexual risk, protection, and disclosure among at-risk Black men who have sex with both men and women (MSMW). Arch Sex Behav. 2008; 37(5):683-696. [PubMed: 18512140]

El-Bassel N, Jemmott JB, Landis JR, Pequegnat W, Wingood GM, Wyatt GE, Bellamy SL. National Institute of Mental Health Multisite Eban HIV/STD prevention intervention for African American HIV serodiscordant couples: A cluster randomized trial. Arch Intern Med. 2010 doi: 2010.261 [pii] 10.1001/archinternmed.2010.261.

Ford CL, Whetten KD, Hall SA, Kaufman JS, Thrasher AD. Black sexuality, social construction, and research targeting 'The Down Low' ('The DL'). Ann Epidemiol. 2007; 17(3):209-216. doi: S1047-2797(06)00261-4 [pii].10.1016/j.annepidem.2006.09.006. [PubMed: 17320787]

Goldbaum G, Perdue TR, Higgins D. Non-gay-identifying men who have sex with men: formative research results from Seattle, Washington. Public Health Rep. 1996; 111(Suppl 1):36-40. [PubMed: 8862155]

Gorbach PM, Murphy R, Weiss RE, Hucks-Ortiz C, Shoptaw S. Bridging sexual boundaries: Men who have sex with men and women in a street-based sample in Los Angeles. J Urban Health. 2009; 86(Suppl 1):63-76. [PubMed: 19543837]

Harawa NT, McCuller WJ, Chavers C, Janson M. HIV risk behaviors among Black/African American and Hispanic/Latina female partners of men who have sex with men and women. AIDS Behav. 2012

Harawa NT, Williams JK, McCuller WJ, Ramamurthi HC, Lee M, Shapiro MF, Cunningham WE. Efficacy of a culturally congruent HIV risk-reduction intervention for behaviorally bisexual black men: results of a randomized trial. AIDS. 2013; 27(12):1979-1988. [PubMed: 24180003]

Harawa NT, Williams JK, Ramamurthi HC, Bingham TA. Perceptions towards condom use, sexual activity, and HIV disclosure among HIV-positive African American men who have sex with men: implications for heterosexual transmission. J Urban Health. 2006; 83(4):682-694. [PubMed: 16736115]

Harawa NT, Williams JK, Ramamurthi HC, Manago C, Avina S, Jones M. Sexual behavior, sexual identity, and substance abuse among low-income bisexual and non-gay-identifying African American men who have sex with men. Arch Sex Behav. 2008; 37(5):748-762. [PubMed: 18546069]

Herbenick D, Schick V, Reece M, Sanders SA, Smith N, Dodge B, Fortenberry JD. Characteristics of condom and lubricant use among a nationally representative probability sample of adults ages 1859 in the United States. J Sex Med. 2013; 10(2):474-483. [PubMed: 23346924]

Ickovics JR, Beren SE, Grigorenko EL, Morrill AC, Druley JA, Rodin J. Pathways of risk: Race, social class, stress, and coping as factors predicting heterosexual risk behaviors for HIV among women. AIDS \& Behavior. 2002; 6(4):339-350. 
Jarama SL, Belgrave FZ, Bradford J, Young M, Honnold JA. Family, cultural and gender role aspects in the context of HIV risk among African American women of unidentified HIV status: an exploratory qualitative study. AIDS Care. 2007; 19(3):307-317. doi: 777036965 [pii]10.1080/09540120600790285. [PubMed: 17453563]

Jeffries WL, Dodge B, Sandfort TG. Religion and spirituality among bisexual Black men in the USA. Cult Health Sex. 2008; 10(5):463-477. doi: 793000377 [pii] 10.1080/13691050701877526. [PubMed: 18568870]

Klevens RM, Fleming PL, Neal JJ, Li J. Knowledge of partner risk and secondary transmission of HIV. Am J Prev Med. 2001; 20(4):277-281. doi: S0749379701002975 [pii]. [PubMed: 11331116]

Laumann, EO.; Gagnon, JH.; Michael, RT.; Michaels, S. The social organization of sexuality: sexual practices in the United States. Chicago: University of Chicago Press; 1994.

Laumann EO, Youm Y. Racial/ethnic group differences in the prevalence of sexually transmitted diseases in the United States: a network explanation. Sex Transm Dis. 1999; 26(5):250-261. [PubMed: 10333277]

Lichtenstein B. Secret encounters: black men, bisexuality, and AIDS in Alabama. Med Anthropol Q. 2000; 14(3):374-393. [PubMed: 11036584]

Martinez-Donate AP, Zellner JA, Sanudo F, Fernandez-Cerdeno A, Hovell MF, Sipan CL, Carrillo H. Hombres Sanos: evaluation of a social marketing campaign for heterosexually identified Latino men who have sex with men and women. Am J Public Health. 2010; 100(12):2532-2540. [PubMed: 21068423]

Maxwell C, Boyle M. Risky heterosexual practices amongst women over 30: Gender, power and long term relationships. AIDS Care. 1995; 7(3):277-293. [PubMed: 7578305]

Murrain M, Barker T. Investigating the relationship between economic status and HIV risk. J Health Care Poor Underserved. 1997; 8(4):416-423. [PubMed: 9334534]

Ober AJ, Y IM, Weiss RE, Gorbach PM, Heimer R, Ouellet LJ, Zule WA. The relative role of perceived partner risks in promoting condom use in a three-city sample of high-risk, low-income women. AIDS Behav. 2011; 15(7):1347-1358. [PubMed: 20976538]

Operario D, Smith CD, Arnold E, Kegeles S. The Bruthas Project: Evaluation of a Community-Based HIV Prevention Intervention for African American Men who have sex with men and women. AIDS Educ Prev. 2010; 22(1):37-48. [PubMed: 20166786]

Paxton KC, Williams JK, Bolden S, Guzman Y, Harawa NT. HIV risk behaviors among African American women with at-risk male partners. Journal of AIDS \& Clinical Research. 2013; 04(07)

Reece M, Briggs L, Dodge B, Herbenick D, Glover R. Perceptions of condom fit and feel among men living with HIV. AIDS Patient Care STDS. 2010; 24(7):435-440. [PubMed: 20578905]

Rietmeijer CA, Bull SS, McFarlane M, Patnaik JL, Douglas JM Jr. Risks and benefits of the internet for populations at risk for sexually transmitted infections (STIs): results of an STI clinic survey. Sexually Transmitted Disease. 2003; 30(1):15-19.

Schmidt MA, Mokotoff ED. HIV/AIDS surveillance and prevention: Improving the characterization of HIV transmission. Public Health Rep. 2003; 118(3):197-204. [PubMed: 12766214]

Schrimshaw EW, Siegel K, Downing MJ Jr. Sexual risk behaviors with female and male partners met in different sexual venues among non-gay-identified, non-disclosing MSMW. Int J Sex Health. 2010; 22(3):167-179. [PubMed: 22059106]

Simon PA, Hu DJ, Diaz T, Kerndt PR. Income and AIDS rates in Los Angeles County. AIDS. 1995; 9(3):281-284. [PubMed: 7755917]

Sobo EJ. Finance, romance, social support, and condom use among impoverished inner-city women. Human Organization. 1995; 54(2):115-128.

Sobo EJ. Narratives of love and the risk of safer sex. Romantic love and sexual behavior: Perspectives from the social sciences. 1998:203-232.

Stokes JP, Peterson JL. Homophobia, self-esteem, and risk for HIV among African American men who have sex with men. AIDS Educ Prev. 1998; 10(3):278-292. [PubMed: 9642425]

The CDC AIDS Community Demonstration Projects Research Group. Community-level HIV intervention in 5 cities: Final outcome dates from the CDC AIDS Community Demonstration Projects. Am J Public Health. 1999; 89:336-345. [PubMed: 10076482] 
Tillerson K. Explaining racial disparities in HIV/AIDS incidence among women in the U.S.: A systematic review. Statistics in Medicine. 2008; 27(20):4132-4143. [PubMed: 18551508]

Voetsch AC, Thomas PE, Johnson AS, Millett GA, Mundey L, Goode C, Heffelfinger JD. Sex with bisexual men among black female students at historically black colleges and universities. J Natl Med Assoc. 2010; 102(12):1198-1205. [PubMed: 21287901]

Washington TA, Brocato J. Exploring the perspectives of substance abusing black men who have sex with men and women in addiction treatment programs. Am J Men's Health. 2011; 5(5):402-412. [PubMed: 21059690]

Weis KE, Liese AD, Hussey J, Coleman J, Powell P, Gibson JJ, Duffus WA. A routine HIV screening program in a South Carolina community health center in an area of low HIV prevalence. AIDS Patient Care STDS. 2009; 23(4):251-258. [PubMed: 19281345]

Whitehead TL. Urban low-income African American men, HIV/AIDS, and gender identity. Med Anthropol Q. 1997; 11(4):411-447. [PubMed: 9408898]

Williams JK, Glover DA, Wyatt GE, Kisler KA, Liu H, Zhang M. A sexual risk and stress reduction intervention for HIV-positive African American MSMW with child sexual abuse histories. Am J Public Health. 2013; 103(8):1476-1484. Epub 2013 Jun 13. [PubMed: 23763412] 
Table 1

Description of sexual partnerships $(\mathrm{p}=31)$ between female participants $(\mathrm{n}=20)$ and their MSMW partners

\begin{tabular}{|c|c|c|c|}
\hline & $\begin{array}{c}\text { Substance-use } \\
\text { involved women }(\mathrm{n}=14) \\
\text { partnerships }\left(\mathrm{p}=\mathbf{2 4} \mathbf{4}^{*}\right)\end{array}$ & $\begin{array}{c}\text { Non-substance-use } \\
\text { involved women }(n=6) \\
\text { partnerships }(p=7)\end{array}$ & $\begin{array}{l}\text { Total } \\
(\mathbf{n}=\mathbf{2 0}) \\
(\mathbf{p}=\mathbf{3 1})\end{array}$ \\
\hline \multicolumn{4}{|c|}{ How They Met } \\
\hline Through friends or family & 6 & 1 & 7 \\
\hline On the street & 5 & 0 & 5 \\
\hline In a store & 4 & 0 & 4 \\
\hline Drug dealing & 3 & 0 & 3 \\
\hline Other (i.e., sex work, buying a trailer, club/bar/hamburger stand) & 3 & 1 & 4 \\
\hline In-patient drug treatment & 2 & 0 & 2 \\
\hline Transitional housing & 2 & 0 & 2 \\
\hline School / dormitory & 0 & 3 & 3 \\
\hline Work & 0 & 1 & 1 \\
\hline
\end{tabular}

Number of Male Bisexual Partners in Lifetime

\begin{tabular}{l|l|l}
\hline More than one & $\mathrm{n}=7$ \\
$\mathrm{n}=7$ & $\mathrm{n}=1 \quad \begin{array}{r}\mathrm{n}=8 \\
\mathrm{n}=5\end{array}$ \\
One & $\mathrm{n}=12$ \\
\hline
\end{tabular}

Partnership Type

\begin{tabular}{l|rrr}
\hline Serious/non-marital/non-cohabitating & 5 & 2 \\
Serious/ongoing - some exchange sex involved & 5 & 5 \\
Engaged/cohabitating & 5 & 5 \\
Married & 3 & 2 \\
Casual & 2 & 2 \\
Customer & 8 & 1 \\
\hline
\end{tabular}

\begin{tabular}{|c|c|c|c|}
\hline \multicolumn{4}{|c|}{ Partnership Length } \\
\hline $5+$ years/long term & 6 & 1 & 7 \\
\hline $2-5$ years & 4 & 4 & 8 \\
\hline 6 months -2 years & 6 & 2 & 8 \\
\hline$<6$ months & 3 & 0 & 3 \\
\hline Intermittent/Not specified & 5 & 0 & 5 \\
\hline
\end{tabular}

Perceived Exclusivity

\begin{tabular}{l|c|c|}
\hline Other partners expected or known & 15 & 1 \\
Exclusive & 7 & 6 \\
Not clear/not assessed & 2 & 0 \\
\hline
\end{tabular}

Types of Sex in Partnership

Any vaginal

22

7

29

Sex Cult. Author manuscript; available in PMC 2015 December 01. 


\begin{tabular}{l|c|c|c}
\hline & $\begin{array}{c}\text { Substance-use } \\
\text { involved women (n=14) } \\
\text { partnerships (p=24) }\end{array}$ & $\begin{array}{c}\text { Non-substance-use } \\
\text { involved women (n=6) } \\
\text { partnerships (p=7) }\end{array}$ & $\begin{array}{c}\text { Total } \\
(\mathbf{n = 2 0}) \\
(\mathbf{p = 3 1})\end{array}$ \\
\hline Any oral & 19 & 3 & 22 \\
Any anal & 9 & 1 & 10 \\
Not discussed & 2 & 0 & 2 \\
\hline & Condom Use in Partnership & & 9 \\
\hline Never used & 8 & 2 & 9 \\
Inconsistently used & 7 & 1 & 5 \\
Use shifted over time & 4 & 0 & 3 \\
Not discussed & 3 & 3 & 5 \\
Consistently used & 2 & & \\
\hline
\end{tabular}

* Includes one woman who described sex with dozens of men that she perceived to be behaviorally bisexual over her lifetime; however, she only provided details of her partnership with one of these men. 